\title{
Pengaruh Pelatihan Kader Posbindu Terhadap Perilaku Deteksi Dini Hipertensi Pada Usia Dewasa
}

\author{
${ }^{1}$ Asri \\ ${ }^{2}$ Sigit Mulyono \\ ${ }^{2}$ Uswatul Khasanah
}

${ }^{1}$ Departemen Keperawatan Komunitas dan Keluarga, Stikes Panrita Husada Bulukumba, Indonesia

${ }^{2}$ Departemen Keperawatan Komunitas, Fakultas Ilmu Keperawatan Universitas Indonesia, Jakarta, Indonesia

${ }^{3}$ Departemen Keperawatan Komunitas Fakultas Ilmu Keperawatan Universitas Muhammadiyah Jakarta,Jakarta, Indonesia

\begin{abstract}
Alamat Korespondensi:
Nama Koresponden : Asri

Bagian : Keperawatan Komunitas

Institusi penulis : Stikes Panrita Husada Bulukumba

No.Hp / Telfn : : 085242199519

Email penulis $\quad$ :asriiffat@gmail.com
\end{abstract}




\begin{abstract}
ABSTRAK
Permasalahan hipertensi pada usia dewasa merupakan hal yang sangat penting untuk menjadi perhatian karena dapat menyebabkan penyakit baik akut maupun kronik seperti penyakit jantung dan pembuluh darah, Pelatihan kader posbindu merupakan suatu kegiatan yang dilakukan sebagai upaya untuk meningkatkan keterampilan dan pengetahuan terhadap deteksi dini hipertensi sehingga dengan adanya kader yang merupakan ujung tombak dalam pelayanan kesehatan dimasyarakat mampu mendeteksi secara dini penyakit hipertensi. Tujuan penelitian ini untuk mengetahui pengaruh pelatihan kader posbindu terhadap perilaku deteksi dini hipertensi pada usia dewasa. Desain penelitian ini menggunakan Quasi Eksperimen One Group pre test Post Tes dengan uji Paired T Test. Populasi dalam penelitian ini adalah seluruh masyarakat yang menderita Hipertensi dengan jumlah sampel sebanyak 84 orang. Hasil penelitian menunjukkan bahwa terdapat perubahan nilai mean rata - rata sebelum dan setelah pelatihan yaitu sebesar 82 kemudian menjadi 87. Hasil analisis uji Paired $T$ test menunjukkan bahwa terdapat pengaruh pelatihan kader posbindu terhadap perilaku deteksi dini Hipertensi dimana nilai $(\mathrm{P}=0,001)$.
\end{abstract}

\title{
Kata Kunci : Pelatihan Kader, Hipertensi, Perilaku Deteksi Dini
}

\begin{abstract}
The problem of hypertension in adulthood is very important to be a concern because it can cause both acute and chronic diseases such as heart and blood vessel disease, Posbindu cadre training is an activity carried out as an effort to improve skills and knowledge of early detection of hypertension so that the presence of cadres who are the spearhead in health services in the community are able to detect hypertension early. The purpose of this study was to determine the effect of posbindu cadre training on early detection of hypertension in adulthood. This research design uses the Quasi One Group Experiment pre-test Post Test with Paired T-Test. The population in this study was all people suffering from hypertension with a total sample of 84 people. The results showed that there was a change in the mean value before and after the training that was equal to 82 then to 87 . The results of the Paired T-test analysis showed that there was an influence of the posbindu cadre training on the behavior of early detection of hypertension where the value $(\mathrm{P}=0.001)$.
\end{abstract}

Keywords: Cadre Training, Hypertension, Early Detection Behavior 


\section{PENDAHULUAN}

Badan Kesehatan Dunia World Health Organization (Organization, 2013) mengatakan bahwa ada 1,13 miliar orang di dunia telah menderita hipertensi artinya bahwa jika ada 3 orang yang diperiksa maka 1 diantaranya akan terdiagnosa hipertensi dan hanya 36,8 \% yang di diagnosis dan rutin untuk memeriksakan kesehatannya dan minum obat, selain itu WHO juga memperkirakan bahwa Jumlah penderita hipertensi di dunia pada tahun 2020 akan mengalami peningkatan terutama pada penduduk usia dewasa yaitu sebesar 1,56 miliar artinya bahwa orang dewasa akan hidup dengan kondisi mengalami Hipertensi, dan diperkirakan setiap tahunnya akan ada 9,4 juta meninggal akibat hipertensi dengan berbagai komplikasi dan penyakit penyerta lainnya WHO, 2015).

Program penyakit tidak menular (PTM) misalnya Hipertensi untuk di Indonesai sudah berjalan sejak 8 tahun yang lalu yaitu sejak tahun 2011 akan tetapi program ini tidak begitu berjalan dengan optimal, program tersebut dikenal dengan nama program Pos Pembinaan Terpadu (Posbindu) yang telah lama dicanangkang oleh Kementrian Kesehatan. Posbindu ini merupakan kegiatan yang melibatkan masyarakat sebagai upaya dalam melakukan pencegahan, melakukan pengawasan terhadap faktor resiko, melakukan rujukan dan tindak lanjut terhadap berbagai masalah kesehatan terutama Hipertensi, dilasanakan secara komprehensif, teratur, dan terencana bersama masyarakat. Kegiatan posbindu ini memiliki tujuan agar masyarakat dapat memeriksakan diri secara teratur, secara dini, diharapkan dapat meningkatkan sikap mawas diri masyarakat terhadap faktor risiko, sehingga kasus - kasus yang ada dimasyarakat dapat dicegah dengan mudah, merubah perilaku masyarakat menjadi sehat, dan mampu memanfaatkan sarana dan prasarana kesehatan yang ada terutama di daerahnya masing - masing, tidak hanya ketika sakit akan tetapi dalam kondisi sehat sehingga penangan lebih awal lebih mudah untuk mencegah terjadinya komplikasi (Direktorat Jenderal Pencegahan dan Pengendalian Penyakit, 2019).

Health Promotion model (HPM) merupakan model keperawatan yang telah di perkenalkan oleh Nola J.Pender pada tahun 1991 dan mampu merubah perilaku manusia dalam melakukan promosi kesehatannya, model tersebut memiliki komponen yang lengkap terutama dalam merubah perilaku manusia. Berdasarkan hasil penelitian yang dilakukan oleh (Fatmi \& Tahlil, 2017) di Kota Banda Aceh mengatakan bahwa terdapat hubungan 
yang signifikan penggunaan HPM terhadap kepatuhan dalam Diet Hipertensi dimana nilai sigifikan yang diperoleh sebesar 0,026. Hasil penelitian yang sama dilakukan oleh (Abdel-All et al., 2018) di Negara India mengatakan bahwa terdapat perbedaan yang signifikan pelatihan pada petugas kesehatan tentang tingkat pengetahuan sebelum dan setelah dilakukan intervensi, dimana skor rata rata pengetahuan sebelumnya yaitu $46 \%$ kemudian mengalami peningkatan setelah intervensi yaitu sebesar $76 \%$.

\section{METODE}

Penelitian ini menggunakan metode penelitian Quasi Eksperiment. Quasi Eksperiment adalah penelitian dengan menguji coba tindakan kepada sekelompok subjek dengan atau tanpa kelompok pembanding dengan menggunakan One Group Pretest - Posttes Design (Hastono, 2017). Sampel dalam peneltian ini adalah masyarakat yang menderita hipertensi di seluruh wilayah Desa Bialo yang berjumlah 84 sampel, tehnik pengambilan sampel menggunakan Purposive Sampling dengan menggunakan kuisioner, analisa data menggunakan program komputerisasi SPSS dengan tehnik pengambilan data dengan memperhatikan keadaan pasien.

\section{HASIL}

Berdasarkan tabel 1, hasil penelitian menunjukkan bahwa dari 84 responden yang menderita hipertensi sebagian besar responden berusia dewasa pertengahan yaitu sebesar $61,9 \%$. Terjadinya hipertensi pada usia dewasa pertengahan dipengaruhi oleh gaya hidup yang tidak sehat seperti merokok, kurang olahraga dan kurang mengkonsumsi makanan yang bergizi (Nisa, 2012). Hasil penelitian dari tabel 1 diketahui bahwa sebagian besar responden berjenis kelamin perempuan yaitu sebesar $82,1 \%$, sebagian besar responden berpendidikan tinggi yaitu sebesar 51,2\% dan sebagian besar responden memiliki status ekonomi rendah yaitu sebesar 85,7 $\%$.

Berdasarkan tabel 2 hasil penelitian menunjukkan bahwa mean skor perilaku deteksi dini hipertensi sebelum dilakukan intervensi sebesar 82,67, dengan skor terendah perilaku yaitu 64 dan skor tertinggi 104, sedangkan mean skor setelah dilakukan intervensi sebesar 87,26 dengan skor terendah 69 dan skor tertinggi 110. Hal ini jika dianalisis terdapat peningkatan nilai mean perilaku deteksi dini sebelum dan setelah intervensi sebesar 4,59, artinya bahwa terjadi peningkatan perilaku deteksi dini hipertensi setelah dilakukan pelatihan.

Hasil penelitian dari tabel 3 menunjukkan bahwa dengan menggunakan uji Paired $T$ Test menunjukkan nilai $\mathrm{P}$ Value sebesar $0,001<\alpha(0,05)$, artinya Ho ditolak yang berarti terdapat pengaruh 
pelatihan kader posbindu terhadap perubahan perilaku deteksi dini Hipertensi.

Menurut Sukiarko (Sukiarko, 2007) Keterampilan merupakan kemampuan melaksanakan tugas /pekerjaan dengan mengunakan angota badan dan peralatan kerja yang tersedia. Ada 3 kemampuan dasar bersifat manusia (human skill), kemampuan teknik (technicall skill) dan kemampuan membuat konsep (conceptual skill).

\section{PEMBAHASAN}

Hasil penelitian berdasarkan distribusi responden pada tabel 1 berdasarakan umur bahwa responden yang terbanyak adalah usia dewasa. Junaidi (Junaidi, 2010) mengatakan bahwa pada usia dewasa hipertensi terjadi karena dipengaruhi oleh gaya hidup seperti merokok, aktifitas fisik dan pola makan disamping itu hal yang sama pun dikatakan oleh (Potter, Perry, Stockert, \& Hall, 2016) bahwa faktor hipertensi terjadi karena faktor riwayat hidup, stress, dan Riwayat keluarga. Kondisi yang sama juga terjadi di Desa Bialo bahwa rata - rata responden usia dewasa pertengahan di daerah tersebut kurang beraktifitas karena mereka adalah ibu - ibu rumah tangga yang lebih cenderung kebanyakan tingggal dirumah dan merasa bahwa dirinya sudah tua.

Berdasarkan tabel 1 pada jenis kelamin yang terbanyak yaitu pada wanita.
Hipertensi terjadi pada wanita lebih banyak dibandingkan dengan laki-laki dengan rasio sekitar 2,29 $\mathrm{mmHg}$ untuk peningkatan darah sistolik. Hal ini terjadi karena perempuan dipengaruhi oleh beberapa hormone termasuk hormone estrogen yang meningkatkan kadar High Density Lipoprotein (LDL) dan melindungi pembuluh darah, pada kondisi pre menopause hormone tersebut mulai mengalami penurunan sehingga tidak terdapat lagi hormone yang melindungi pembuluh darah dan resiko hipertensi pun dapat terjadi (Kartikasari, 2012).

Menurut (Allender, Rector, Rector, \& Warner, 2013) bahwa faktor yang menyebabkan perempuan lebih banyak yang menderita hipertensi karena kurangnya aktifitas fisik, obesitas dan kolesterol. Berdasarkan tabel 1 bahwa tingkat pendidikan yang terbanyak yang terkena Hipertensi adalah pada pendidikan tinggi. Hubungan antara tingkat pendidikan dengan hipertensi bisa dikatakan hubungan tidak langsung. Hal ini karena adanya peran pengetahuan, dimana tingkat pendidikan akan mempengaruhi pengetahuan seseorang, pengetahuan yang baik kemudian akan menimbulkan kesadaran seseorang. Kesadaran masyarakat tentang faktor resiko hipertensi akan membuat mereka dengan sadar merubah gaya hidupnya 
(Amu, 2015). Kondisi berbeda disampaikan oleh Sudarma (2008) bahwa tingkat pendidikan yang tinggi tidak menjamin sesorang untuk terkena hipertensi karena dengan pendidikan yang tinggi tidak dipengaruhi oleh kemampuan akan tetapi perlu dibuktikan juga dengan kemauan untuk melakukan pencegahan, olehnya itu perlu kesinambungan antara kemampuan dan kemauan yang memadai dalam diri masyarakat.

Berdasarkan tabel 1, dari segi tingkat ekonomi didapatkan bahwa tingkat ekonomi rendah mempengaruhi terjadinya Hipertensi. Menurut (Longo-Mbenza, Luila, Mbete, \& Vita, 1999) bahwa tingkat status ekonomi sangat berhubungan dengan kejadian Hipertensi, menurut (Thurston \& Matthews, 2009) bahwa terdapat mekanisme yang kompleks sehingga tingkat sosial ekonomi yang rendah dapat meningkatkan tekanan darah dan resiko penyakit kardiovaskuler. Pada orang dewasa dengan tingkat sosial ekonomi yang rendah hal ini dapat dihubungkan dengan kebiasaan merokok, kurangnya aktifitas fisik, tingginya tingkat stress akibat kebutuhan hidup, permasalahan kesehatan mental, tingginya angka kegemukan, dan resistensi insulin dibandingkan dengan tingkat ekonomi yang tinggi.
Berdasarkan tabel 2 didapatkan bahwa terjadi perubahan nilai mean rata rata perubahan perilaku masyarakat yang menderita hipertensi terutama dari segi keterampilan. Keterampilan merupakan rancang dari proses pembelajaran untuk mengubah perilaku menjadi cekatan secara psikomotor dalam melakukan tugastugasnya. Masyarakat harus mampu melakukan tugasnya seperti melakukan deteksi dini hipertensi serta mampu mencegah terjadinya hipertensi. Bila masyarakat tidak terampil mendeteksi ini tentu akan berdampak pada komplikasi yang lebih parah (Direktorat Jenderal Pencegahan dan Pengendalian Penyakit, 2019).

Pelatihan yang peneliti lakukan sesuai dengan konsep Health Promotion Model (HPM) bahwa kader posbindu dibekali dengan konsep, teori dan praktik. Konsep dan teori yang diberikan berupa mengenal hipertensi secara detail dimulai dengan pengertian hipertensi sampai dengan pengobatan, dan secara skill masyarakat juga di latih tentang pemeriksaan tekanan darah, mengukur berat badan dan tinggi badan serta pengukuran lingkar perut.

Menurut Tanjung (2003) yang dikutip dari (Laraeni \& Wiratni, 2014), pelatihan merupakan suatu proses belajar mengajar terhadap pengetahuan dan 
keterampilan tertentu serta sikap agar semakin terampil dan mampu melaksanakan tanggung jawabnya dengan semakin baik, sesuai dengan standar. Pelatihan berarti mengubah pola perilaku karena dengan pelatihan maka akhirnya akan menimbulkan perubahan perilaku.

Keterampilan teknik adalah kemampuan untuk menggunakan alat, prosedur dan teknik yang berhubungan dengan bidangnya. Keterampilan manusia adalah kemampuan untuk dapat bekerja, mengerti dan mengadakan motifasi kepada orang lain. Keterampilan konsep adalah kemampuan untuk melakukan kerja sama didalam pekerjaan, pekerjaan itu dapat memberikan keterampilan sedangkan keterampilan masyarakat lebih pada keterampilan teknis. Pelatihan merupakan bagian dari investasi Sumber Daya Manusia (human investment) untuk meningkatkan kemampuan dan keterampilan kerja dan dengan demikian meningkatkan kinerja seseorang.

Berdasarkan tabel 3 bahwa terdapat hubungan yang signifikan pemberian pelatihan kepada masyarakat dalam melakukan deteksi dini Hipertensi. Hasil penelitian tersebut sejalan dengan Penelitian (Plowright et al., 2018) bahwa setelah intervensi pelatihan kepada pekerja kesehatan dimasyarakat dilakukan terjadi peningkatan skor pengetahuan dan sikap. Perubahan pengetahuan dan sikap ini secara statistik signifikan $(\mathrm{p}<0,001)$ dan perbedaan persentase nilai mean lebih dari 45 poin persentase atau empat standar deviasi). Semua Petugas Kesehatan masyarakat melaporkan tingkat kepuasan yang tinggi terhadap pelatihan yang diberikan dan adanya peningkatan dengan ditandai dengan rasa percaya diri dalam memberikan informasi kesehatan kepada klien, selain itu pelatihan tersebut efektif menekan biaya kesehatan dengan meningkatkan kinerja berbasis lapangan.

Hasil penelitian ini sejalan dengan penelitian yang dilakukan oleh (Maulidta \& Prasetyorini, 2017) di semarang bahwa terdapat pengaruh pelatihan terhadap perubahan perilaku responden dimana nilai p Value sebesar 0,000. Secara konseptual menurut (Notoatmojo, 2010), perubahan pengetahuan, sikap, psikomotor mempengaruhi perilaku manusia, beliau juga mengatakan bahwa apabila penerimaan perilaku baru didasari oleh pengetahuan, kesadaran, sikap positif maka perilaku tersebut akan bersifat langgeng. Dengan demikian semakin tinggi tingkat pengetahuan seseorang maka semakin tepat dalam menentukan perilaku serta semakin cepat pula untuk mencapai tujuan meningkatkan derajat kesehatan. 
Pelatihan kepada masyarakt merupakan sesuatu yang sangat penting karena merubah dari 3 aspek penting yaitu pengetahuan, sikap, psikomotor dengan berubahnya ketiga aspek tersebut tentu intervensi tersebut memiliki peranan yang sangat penting dalam merubah perilaku, hal ini sejalan dengan konsep Health Promotion Model (HPM) yang telah di perkenalkan oleh Nola J.Pender bahwa untuk merubah perilaku seseorang diperlukan intervensi terhadap karakteristik dan tingkat perilaku sebelumnya, sehingga sesorang dengan intervensi tersebut mampu mengarahkan perilaku ke hal - hal yang lebih baik (Parsons, Pender, \& Murdaugh, 2011).

\section{KESIMPULAN DAN SARAN}

Sebagian besar responden berusia Dewasa pertengahan, mayoritas responden berjenis kelamin perempuan, hampir sama responden yang berpendidikan tinggi dengan yang rendah serta sebagian besar berstatus ekonomi rendah, Terjadi peningkatan perilaku deteksi dini hipertensi setelah dilakukan pelatihan kepada masyarakat, Terdapat perbedaan perilaku deteksi dini hipertensi setelah dilakukan pelatihan kepada masyarakat. Berdasarkan kesimpulan tersebut diatas disarankan untuk memonitoring dan melakukan evaluasi dari Dinas Kesehatan setempat untuk tetap mempertahankan kemampuan masyarakat agar tetap di perbaharui sesuai dengan kondisi terkini.

Puskesmas diharapkan dapat memfasilitasi kegiatan pemberdayaan masyarakat dalam rangka peningkatan kemampuan masyarakat dalam melakukan deteksi dini. Selain itu kegiatan ini dapat dijadikan sebagai intervensi yang berkelanjutan bagi Puskesmas sehingg memiliki dampak yang nyata terhadap peningkatan kesehatan masyarakat di wilayahnya tempat dimana mereka tinggal serta lebih dini mengontrol terhadap perilaku deteksi dini bagi masyarakat yang menderita hipertensi.

\section{DAFTAR PUSTAKA}

Abdel-All, M., Thrift, A. G., Riddell, M., Thankappan, K. R. T., Mini, G. K., Chow, C. K., ... Joshi, R. (2018). Evaluation of a training program of hypertension for accredited social health activists (ASHA) in rural India. BMC Health Services Research, 18(1), 1-11. https://doi.org/10.1186/s12913-0183140-8

Allender, J., Rector, C., Rector, C., \& Warner, K. (2013). Community \& public health nursing: Promoting the public's health. Lippincott Williams \& Wilkins.

Amu, D. A. (2015). Hipertensi di Wilayah

Perkotaan dan Pedesaan di

Indonesia.

Direktorat Jenderal Pencegahan dan

Pengendalian Penyakit. (2019).

Petunjuk Teknis POSBINDU Bagi

Kader, 1-60.

Fatmi, E., \& Tahlil, T. (2017). Faktor 
Determinan Kepatuhan Diet pada

Pasien Hipertensi dengan Pendekatan

Health Promotion Model (HPM). In

Prosiding Seminar Nasional

Pascasarjana Unsyiah.

Hastono, S. P. (2017). Statistik kesehatan.

Junaidi, I. (2010). Hipertensi, Pengenalan,

Pencegahan, dan Pengobatan.

Jakarta: PT Bhuana Ilmu Populer.

Kartikasari, A. (2012). Faktor Risiko

Hipertensi pada Masyarakat di Desa

Kabongan Kidul, Kabupaten

Rembang. Univer.

https://doi.org/10.1109/CAMSAP.201

5.7383821

Laraeni, Y., \& Wiratni, A. (2014).

Pengaruh Penyegaran Kader

Terhadap Pengetahuan dan

Keterampilan Kader Posyandu

Menggunakan Dacin di Wilayah

Kerja Puskesmas Dasan Cermen

Kecamatan Sandubaya Kota

Mataram. Jurnal Media Bina Insani.

ISSN, (1978-3787).

Longo-Mbenza, B., Luila, E. L., Mbete, P.,

\& Vita, E. K. (1999). Is

hyperuricemia a risk factor of stroke

and coronary heart disease among

Africans? International Journal of

Cardiology, 71(1), 17-22.

Maulidta, K. W., \& Prasetyorini, H.

(2017). Upaya Peningkatan

Ketrampilan Kader Posyandu Dalam

Pengukuran Tekanan Darah Melalui

Pelatihan Kader. Jurnal Ilmu Dan

Teknologi Kesehatan, 7(2).

Nisa, I. (2012). Ajaibnya terapi herbal tumpas penyakit darah tinggi.

Jakarta: Dunia Sehat.

Notoatmojo, S. (2010). Ilmu perilaku

manusia. Jakarta: Rineka Cipta.

Organization, W. H. (2013). A global brief

on hypertension: silent killer, global public health crisis: World Health

Day 2013. World Health

Organization.

Parsons, M. A., Pender, N. J., \&

Murdaugh, C. L. (2011). Health

promotion in nursing practice.

Pearson Higher Ed.

Plowright, A., Taylor, C., Davies, D., Sartori, J., Hundt, G. L., \& Lilford, R.

J. (2018). Formative evaluation of a training intervention for community health workers in South Africa: A before and after study. PLOS ONE, 13(9), 1-15.

https://doi.org/10.1371/journal.pone.0 202817

Potter, P. A., Perry, A. G., Stockert, P., \& Hall, A. (2016). Fundamentals of Nursing-E-Book. Elsevier Health Sciences.

Sukiarko, E. (2007). Pengaruh Pelatihan dengan Metode Belajar Berdasarkan Masalah terhadap Pengetahuan dan Keterampilan Kader Gizi dalam Kegiatan Posyandu Studi Di Kecamatan Tempuran Kabupaten Magelang The Effect of Problem Based Training on Knowledge and Skills of Nutrition . program Pascasarjana Universitas Diponegoro. Thurston, R. C., \& Matthews, K. A. (2009). Racial and socioeconomic disparities in arterial stiffness and intima media thickness among adolescents. Social Science \& Medicine, 68(5), 807-813. 
Tabel 1. Distribusi Frekuensi Responden di Desa Bialo Wilayah Kerja Puskesmas Ponre Kec.Gantarang Kab.Bulukumba

\begin{tabular}{lcc}
\hline \multicolumn{1}{c}{ Variabel } & Frekuensi & Persentase (\%) \\
\hline Usia & & \\
Usia Dewasa muda & 32 & 38,1 \\
Usia Dewasa Pertengahan & 52 & 61,9 \\
\hline Jenis Kelamin & & \\
Laki - Laki & 15 & 17,9 \\
Perempuan & 69 & 82,1 \\
\hline Pendidikan & & \\
Pendidikan Rendah & 41 & 48,8 \\
Pendidikan Tinggi & 43 & 51,2 \\
\hline Status Ekonomi & & \\
Ekonomi Rendah & 72 & 85,7 \\
Ekonomi Tinggi & 12 & 14,3 \\
\hline Total & $\mathbf{8 4}$ & $\mathbf{1 0 0 , 0}$ \\
\hline
\end{tabular}

Tabel 2. Rata - rata Skor Perilaku deteksi dini Hipertensi sebelum dan setelah dilakukan intervensi

\begin{tabular}{ccccc}
\hline Pengukuran & Mean & n & Standar Deviasi & Minimal- Maksimal \\
\hline Sebelum & 82,67 & 84 & 8,516 & $64-104$ \\
\hline Setelah & 87,26 & 84 & 8,238 & $69-110$ \\
\hline
\end{tabular}

Tabel 3. Pengaruh pelatihan kader posbindu terhadap perilaku deteksi dini Hipertensi

\begin{tabular}{cccccc}
\hline Skor Perilaku & Mean & $\begin{array}{c}\text { Standar } \\
\text { Deviasi }\end{array}$ & T Hitung & 95 \% CI & P Value \\
\cline { 2 - 3 } Sebelum & 82,67 & 8,516 & $-8,614$ & $(-5.656)-$ & 0,001 \\
\cline { 1 - 3 } Setelah & 87,26 & 8,238 & & $(8,614)$ & \\
\hline
\end{tabular}

